\title{
PENGGUNAAN FMEA DALAM MENGIDENTIFIKASI RESIKO KEGAGALAN PROSES PRODUKSI SARUNG ATM (ALAT TENUN MESIN) (STUDI KASUS PT. ASAPUTEX JAYA TEGAL)
}

\author{
Nia Budi Puspitasari, Arif Martanto ${ }^{*}$ \\ ${ }^{1,2)}$ Program Studi Teknik Industri, Fakultas Teknik, Universitas Diponegoro \\ Jl. Prof. Sudharto, Tembalang, Semarang
}

\begin{abstract}
Abstrak
Pengendalian kualitas merupakan salah satu hal yang penting untuk mempertahankan reputasi perusahaan di mata konsumen. PT. Asaputex Jaya adalah perusahaan textil yang bergerak dalam bidang sarung tenun. Pada saat ini cacat produk yang terjadi pada perusahaan masih ada yang diluar dari ketentuan batas perusahaan yaitu diatas angka persentase yang telah ditetapkan oleh perusahaan yaitu sebesar $2 \%$. Sehingga perusahaan segera melakukan perbaikan agar tidak terjadi waste yang merugikan perusahaan. Dengan adanya pengendalian kualitas secara baik dan benar, maka akan diperoleh produk yang dapat memenuhi keinginan konsumen. Salah satu tool yang digunakan untuk membantu pengendalian kualitas adalah menggunakan metode Failure Modes and Effects Analysis (FMEA). Penggunaan FMEA mampu mengidentifikasi resiko kegagalan yang terjadi selama proses produksi pada pembuatan sarung tenun. Tujuan penelitian ini adalah menganalisa moda kegagalan yang menyebabkan cacat produk dengan menggunakan metode FMEA, mendapatkan resiko kegagalan proses produksi terbesar dalam nilai RPN (Risk Priority Number), memberikan usulan perbaikan untuk produksi selanjutnya. Berdasarkan pengolahan dengan metode FMEA dapat mengidentifikasi moda kegagalan yang terjadi pada proses pembuatan sarung tenun. Moda kegagalan potensial pada proses pembuatan sarung tenun dengan alat tenun mesin (ATM) pada PT. Asaputex Jaya terdiri dari 14 jenis kegagalan.
\end{abstract}

Kata Kunci : kualitas; alat tenun mesin; failure mode and effect analysis; risk priority number

\begin{abstract}
Quality control is one of the things that are important to maintain the company's reputation in the eyes of consumers. PT. Asaputex Jaya is a company engaged in the field of textile woven sarongs. At this time the product defect that occurs in companies that still exist outside the corporate limits of the provisions of the above percentage figures set by the company which is $2 \%$. So the company immediately repairs to prevent harmful waste. With the quality control is good and true, it will obtain the products that can meet customer demand. One of the tools used to help control quality is to use the method of Failure Modes and Effects Analysis (FMEA). The use of FMEA is able to identify the risk of failure that occurs during the production process in the manufacture of woven sarongs. The purpose of this study was to analyze the failure modes that cause defective product using the FMEA method, get the biggest risk of failure of the production process in the value of the RPN (Risk Priority Number), and provide suggestions for improvement to the next production. Based on the processing of the FMEA method can identify failure modes that occur in the process of making woven sarongs. Potential failure modes in the process of making sarong with alat tenun mesin (ATM) at PT. Asaputex Jaya consist of 14 types of failures.
\end{abstract}

Keywords: quality; alat tenun mesin; failure mode and effect analysis; risk priority number

\section{Pendahuluan}

Pada dewasa ini dunia industri berkembang pesat, yang mengakibatkan beragam produk yang dihasilkan.

\footnotetext{
"Penulis Korespondensi.

E-mail:niabudipuspitasari@gmail.com, manufestoartan@yahoo.com
}

J@TI Undip, Vol IX, No 2, Mei 2014
Keberagaman produk tersebut memaksa produsen untuk terus meningkatkan kualitas produk yang dihasilkan sesuai dengan keinginan konsumen. Akan tetapi masih banyak juga pelaku industri yang kurang memperhatikan kualitas produk. Produk yang cacat adalah sumber utama pemborosan. Tidak sedikit 
perusahaan menghadapi masalah serius karena produk cacat yang menimbulkan klaim dari konsumen. Jika produk cacat lolos kepada konsumen dan kemudian menimbulkan kerugian, maka perusahaan harus mengganti kerugian yang dialami konsumen. Salah satu dampak negatif yang diakibatkan adalah runtuhnya reputasi perusahaan di mata konsumen. Bila situasi demikian tidak diatasi dengan segera, perusahaan akan kehilangan konsumen potensial. Dengan adanya pengendalian kualitas secara baik dan benar, maka akan diperoleh produk yang dapat memenuhi keinginan konsumen. Salah satu tool yang digunakan untuk membantu pengendalian kualitas adalah menggunakan metode Failure Modes and Effects Analysis (FMEA).

FMEA merupakan sebuah metodologi yang digunakan untuk mengevaluasi kegagalan terjadi dalam sebuah sistem, desain, proses, atau pelayanan (service). Identifikasi kegagalan potensial dilakukan dengan cara pemberian nilai atau skor masing - masing moda kegagalan berdasarkan atas tingkat kejadian (occurrence), tingkat keparahan (severity), dan tingkat deteksi (detection) (Stamatis, 1995).

Secara umum, terdapat dua tipe FMEA, FMEA desain dan FMEA proses. Pada FMEA desain, pengamatan difokuskan pada desain produk. Sedangkan FMEA proses, pengamatan difokuskan pada kegiatan proses produksi. Metode yang diterapkan pada penelitian ini adalah FMEA proses, karena pengamatan hanya dilakukan pada kegiatan proses produksi yang sedang berlangsung dan tidak memperhatikan desain produk. Tujuan penerapan metode ini adalah untuk meminimasi kemungkinan terjadi cacat (defect).

PT Asaputex Jaya merupakan perusahaan textil yg bergerak di bidang pembuatan sarung tenun. Pada PT
Asaputex Jaya terdapat 2 proses produksi pembuatan sarung, yaitu ATBM (Alat Tenun Bukan Mesin) dan ATM (Alat Tenun Mesin). Pada proses produksi sarung tenun ATM menetapkan 4 jenis cacat (defect) dalam standar, yaitu

a. Cacat kain sarung ke arah lusi/bahan

Cacat kain sarung ke arah lusi yaitu arah kain yang manjalur dari arah vertikal kain sarung. Cacat yang termasuk diantaranya ini adalah salah cucuk, salah strip, panjang sarung tidak standar,sisir rusak dll.

b. Cacat kain sarung ke arah pakan

Cacat ke arah pakan yaitu arah kain yang menjalur horizontal dari kain sarung. Cacat yang termasuk dalam kategori ini misalnya pakan salah strip, pakan campur, pakan putus, pakan rangkap dll

c. Cacat kain sarung yang lain

Cacat ini termasuk dari bagian sarung tenun secara keseluruhan misalnya yaitu sarung kotor kena oli, sarung robek, sarung berbulu, kain kena kotoran, kena anyaman benda lain, dll.

d. Pemotongan/penjahitan.

Yang berhubungan dengan proses penjahitan atau pemotongan pada sarung tenun,misalnya yaitu jahitan tidak terarah, jahitan tidak tersambung, pemotongan yang tidak sesuai dll

Pada PT Asaputex Jaya Tegal, pengendalian kualitas yang dilakukan masih kurang maksimal. Hal ini dapat dilihat dari adanya sejumlah produk yang cacat dalam setiap kali produksi. Berdasarkan data historis yang didapatkan, bahwa prosentase cacat yang telah dilakukan pada bulan Agustus 2010 sampai dengan Juli 2011 masih sangat tinggi, frekuensi cacat produk sarung tenun ATM PT Asaputex Jaya Tegal dapat dilihat pada Tabel 1.

Tabel 1. Data historis jumlah frekuensi cacat produk sarung tenun ATM PT Asaputex Jaya Tegal selama Bulan Agustus 2010- Juli 2011

\begin{tabular}{cccc}
\hline Bulan & $\begin{array}{c}\text { Jumlah } \\
\text { Cacat }(\boldsymbol{p c s})\end{array}$ & $\begin{array}{c}\text { Jumlah Produk } \\
\text { Jadi }(\boldsymbol{p c s})\end{array}$ & $\begin{array}{c}\text { Persentase Jumlah } \\
\text { Cacat (\%) }\end{array}$ \\
\hline Agustus 2010 & 853 & 45947 & $1,86 \%$ \\
September 2010 & 1017 & 45783 & $2,22 \%$ \\
Oktober 2010 & 880 & 45920 & $1,92 \%$ \\
November 2010 & 857 & 45943 & $1,87 \%$ \\
Desember 2010 & 972 & 45828 & $2,12 \%$ \\
Januari 2011 & 546 & 30654 & $1,78 \%$ \\
Februari 2011 & 484 & 30716 & $1,58 \%$ \\
Maret 2011 & 580 & 30620 & $1,89 \%$ \\
April 2011 & 545 & 30655 & $1,78 \%$ \\
Mei 2011 & 1.193 & 45.607 & $2,60 \%$ \\
Juni 2011 & 1.060 & 45.740 & $2,31 \%$ \\
Juli 2011 & 1.291 & 45.509 & $2,83 \%$ \\
\hline
\end{tabular}


Pada Tabel 1 menunjukan angka persentase jumlah produk yang cacat (defect) yang dialami oleh perusahaan ini masih ada angka yang cukup tinggi diatas angka persentase yang telah ditetapkan oleh perusahaan yaitu sebesar $2 \%$. Akibat yang ditimbulkan pada perusahaan apabila adanya cacat yang melebihi ketentuan yaitu banyaknya sisa kain sarung atau kain perca yang dihasilkan menjadikan waste. Selain itu, apabila ada cacat sampai lolos sudah sampai hingga tahapan pengepakan, maka sarung tersebut akan diturunkan grade sesuai dengan kondisi sarung yang cacat. Hal itu akan membuat kerugian bagi perusahaan karena produk sarung yang kualitas rendah tidak bisa diekspor dan tentu saja harganya jauh di bawah harga ekspor. Sedangkan pangsa pasar dari PT.Asaputex Jaya adalah Timur Tengah dan beberapa negara Afrika sehingga kualitas dari sarung tersebut harus baik. Apabila hal ini terjadi secara terus - menerus maka akan merugikan pihak perusahaan. Maka, perlu bagi perusahaan mengetahui jenis kegagalan yang dapat timbul selama proses produksi. Berdasar potensi kegagalan yang ada, perlu ditetapkan jenis kegagalan yang harus diprioritaskan terlebih dahulu agar segera diperbaiki sehingga tidak diperoleh kembali produk gagal dengan jenis kegagalan proses yang sama. Berdasarkan permasalahan tersebut, maka perlu dilakukan tujuan penelitian adalah mengidentifikasi masalah penentuan prioritas jenis kegagalan dalam proses Failure Mode and Effects Analysis (FMEA) dengan demikian diharapkan kualitas produk sarung tenun ATM dari PT Asaputex Jaya Tegal dapat meningkat.

\section{Metodologi Penelitian}

Metodologi penelitian berisi mengenai langkah langkah yang dilakukan dalam penelitian. Pada penelitian ini, metodologi penelitian ditunjukkan pada Gambar 1.

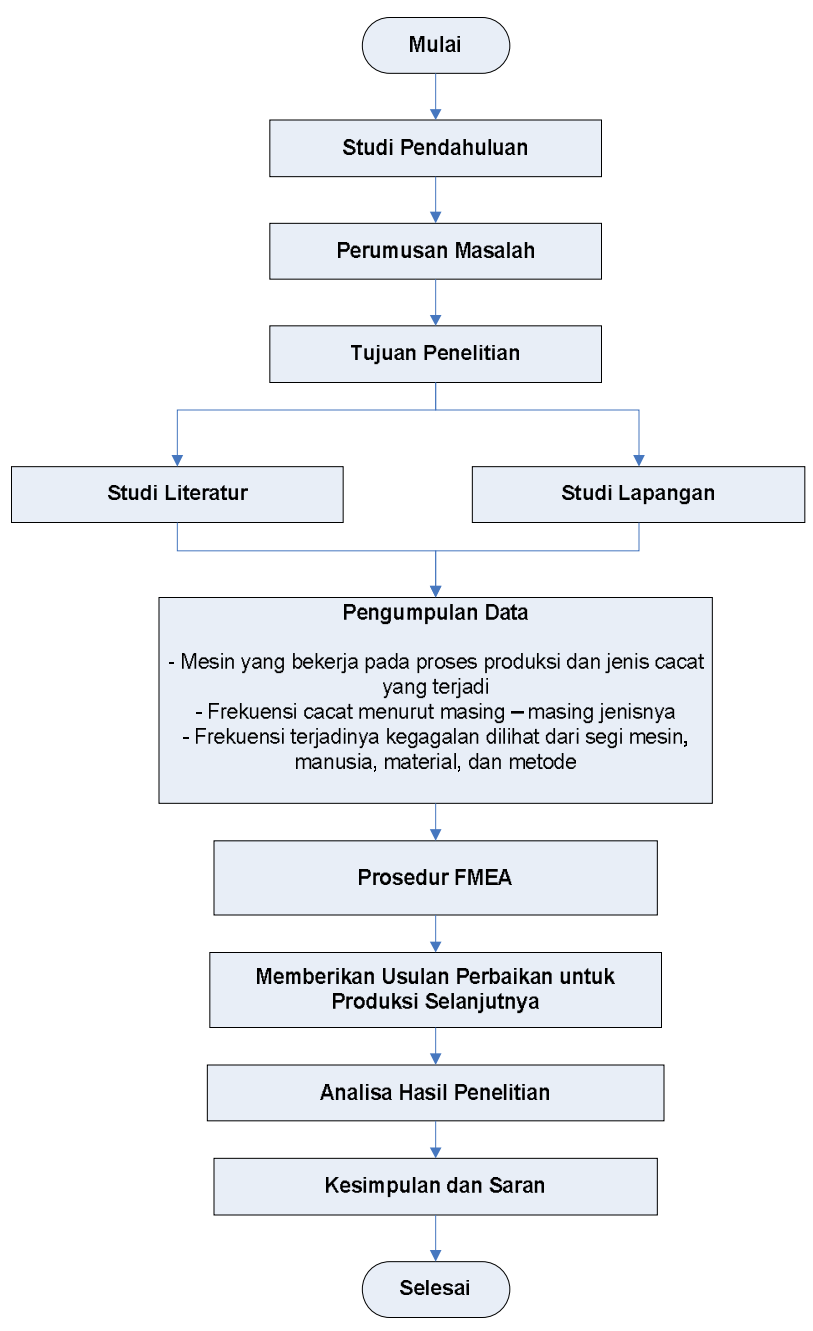

Gambar 1. Metodologi Penelitian 


\section{Kualitas}

Pada dasarnya sistem kualitas modern dapat dicirikan oleh lima karakteristik sebagai berikut :

a. Sistem kualitas modern berorientasi pada pelanggan

b. Sistem kualitas modern dicirikan oleh adanya pastisipasi aktif yang dipimpin oleh manajemen puncak dalam proses peningkatan kualitas secara terus - menerus

c. Sistem kualitas modern dicirikan oleh adanya pemahaman dari setiap orang terhadap tanggung jawab spesifik terhadap kualitas

d. Sistem kualitas modern dicirikan oleh adanya aktifitas yang berorientasi kepada tindakan pencegahan kerusakan, bukan berfokus pada upaya untuk mendeteksi kerusakan saja

Sistem kualitas modern dicirikan oleh adanya suatu filosofi yang menganggap bahwa kualitas merupakan "jalan hidup" (way of life). (Gasperz, 2005)

\section{Kegagalan}

Terdapat 3 (tiga) jenis kegagalan produk yang terjadi pada kegiatan produksi, yaitu :

1. Dijual Langsung

Kegagalan yang djual langsung adalah jenis produk gagal atau produk cacat yang tidak lulus terhadap inspeksi, namun masih layak untuk dijual langsung kepada konsumen yang siap menampung produk jenis cacat seperti ini.

2. Dikerjakan Kembali (reworked)

Kegagalan ini merupakan jenis cacat yang dapat dimasukkan ke dalam proses produksi lagi untuk diproses lebih lanjut, untuk menghasilkan suatu produk lain dalam kondisi yang tidak cacat lagi.

3. Dibuang Langsung (scrap)

Kegagalan ini merupakan jenis produk cacat yang paling parah. Artinya produk cacat ini merupakan hasil dari proses produksi yang sudah tidak ada artinya lagi. Dalam artian, produk cacat tersebut sudah tidak mungkin pula untuk dijual, karena tingkat kegagalan jenis produk ini, merupakan kegagalan yang tidak dapat diusahakan apa - apa.

\section{Failure Modes and Effects Analysis (FMEA)}

FMEA merupakan sebuah teknik yang digunakan untuk mencari, mengidentifikasi, dan menghilangkan kegagalan potensial, error, dan masalah yang diketahui dari sistem, desain, proses, atau jasa sebelum hal tersebut sampai ke konsumen. FMEA disini adalah FMEA Process untuk mendeteksi risiko yang teridentifikasi pada saat proses.

\section{Process FMEA (PFMEA)}

PFMEA merupakan salah satu tipe dari FMEA. PFMEA mengutamakan analisis moda kegagalan melalui proses produksi, dan tidak bergantung pada perubahan desain produk yang dapat menyebabkan kegagalan pada suatu proses.

PFMEA biasanya diselesaikan menurut pertimbangan tenaga kerja, mesin, metode, material, pengukuran, dan lingkungan. Setiap komponen - komponen tersebut memiliki komponen masing - masing, yang bekerja secara individu, bersama, atau bahkan merupakan sebuah interaksi untuk menghasilkan sebuah kegagalan.

\section{Tingkat Keparahan (Severity)}

Severity adalah penilaian terhadap keseriusan dari efek yang ditimbulkan. Dalam arti setiap kegagalan yang timbul akan dinilai seberapa besarkah tingkat keseriusannya. Terdapat hubungan secara langsung antara efek dan severity. Sebagai contoh, apabila efek yang terjadi adalah efek yang kritis, maka nilai severity pun akan tinggi. Dengan demikian, apabila efek yang terjadi bukan merupakan efek yang kritis, maka nilai severity pun akan sangat rendah.

\section{Tingkat Kejadian (Occurance)}

Occurance adalah kemungkinan bahwa penyebab tersebut akan terjadi dan menghasilkan bentuk kegagalan selama masa penggunaan produk. Occurance merupakan nilai rating yang disesuaikan dengan frekuensi yang diperkirakan dan atau angka kumulatif dari kegagalan yang dapat terjadi.

\section{Metode Deteksi (Detection)}

Nilai detection diasosiasikan dengan pengendalian saat ini. Detection adalah pengukuran terhadap kemampuan mengendalikan / mengontrol kegagalan yang dapat terjadi.

\section{Risk Priority Number (RPN)}

Nilai ini merupakan produk dari hasil perkalian tingkat keparahan, tingkat kejadian, dan tingkat deteksi. RPN menentukan prioritas dari kegagalan. RPN tidak memiliki nilai atau arti. Nilai tersebut digunakan untuk meranking kegagalan proses yang potensial.

Nilai RPN dapat ditunjukkan dengan persamaan sebagai berikut :

$\mathrm{RPN}=$ severity $\mathrm{x}$ occurrence $\mathrm{x}$ detection

\section{Hasil dan Pembahasan}

Analisa Faktor - faktor Penyebab Kegagalan Produk Woven Bag dengan Menggunakan Metode Failure Mode and Effects Analysis (FMEA)

Tahapan yang harus dilakukan pada metode ini adalah sebagai berikut :

- Menentukan komponen dari sistem / alat yang akan dianalisa

- Mengidentifikasi moda kegagalan dari proses yang diamati

- Mengdidentifikasi akibat / ( potential effect) yang ditimbulkan potential failure 
- Mengidentifikasi penyebab ( potential cause) dari moda kegagalan yang terjadi pada proses yang berlangsung

- Menetapkan nilai - nilai ( dengan cara observasi lapangan dan brainstorming )

- Menentukan nilai RPN , yaitu nilai yang menunjukkan keseriusan dari potential failure

Pada produk sarung tenun PT. Asaputex Jaya Tegal, penentuan moda kegagalan potensial dilihat dari material yang digunakan, metode kerja, tenaga kerja, maupun masing - masing mesin atau proses yang berjalan dapat dilihat pada Tabel 2 .

Setelah ditentukan nilai severity, occurrence, dan detection, selanjutnya dapat dilakukan perhitungan nilai RPN untuk masing - masing moda kegagalan tersebut. Tabel 3 merupakan urutan moda kegagalan berdasarkan nilai RPN terbesar. Moda kegagalan dengan nilai RPN terbesar merupakan prioritas untuk dilakukan tindakan korektif.

Tabel 2. Moda Kegagalan Potensial produk sarung tenun PT. Asaputex Jaya Tegal

\begin{tabular}{cl}
\hline Nama Alat / Proses & \multicolumn{1}{c}{ Moda Kegagalan Potensial } \\
\hline Mesin Relling & Tenaga mesin relling kurang dari $5 \mathrm{HP}$ \\
Dyeing/ Pewarnaan & Panas dari boiler $<120^{\circ} \mathrm{C}$ \\
Centrifugal atau Pemerasan & Motor pemutar drum rusak \\
Winding & Motor pemutar rusak \\
& Tenaga pengantar silinder kurang dari $5 \mathrm{HP}$ \\
Warping & Sensor elektrik ring Rusak \\
& Kampas rem rusak \\
Mesin Relling & Motor penggerak bum hani rusak \\
Dyeing/ Pewarnaan & Tenaga mesin relling kurang dari 5 HP \\
Centrifugal atau Pemerasan & Panas dari boiler <120 C \\
Winding & Motor pemutar drum rusak \\
& Motor pemutar rusak \\
Warping & Tenaga pengantar silinder kurang dari $5 \mathrm{HP}$ \\
& Sensor elektrik ring Rusak \\
& Kampas rem rusak \\
Pirn Winder & Motor penggerak bum hani rusak \\
& Alat otomatis pergantian palet rusak \\
& Motor penggerak pemintal palet rusak \\
& Rem drum tenun tidak bekerja \\
Weaving dan pencucukan & Shuttle rusak \\
& Connecting patah \\
Pemotongan dan Penjahitan & Mesin jahit tidak menjahit dengan baik \\
\hline
\end{tabular}

Tabel 3 Ranking RPN untuk Masing - masing Moda Kegagalan

\begin{tabular}{clr}
\hline Ranking & \multicolumn{1}{c}{ Moda Kegagalan } & RPN \\
\hline $\mathbf{1}$ & Connecting patah & 280 \\
$\mathbf{2}$ & Shuttle rusak & 144 \\
$\mathbf{3}$ & Motor penggerak pemintal palet rusak & 128 \\
$\mathbf{4}$ & Kampas rem rusak & 100 \\
$\mathbf{5}$ & Tenaga mesin relling kurang dari 5 HP & 96 \\
$\mathbf{6}$ & Motor penggerak bum hani rusak & 96 \\
$\mathbf{7}$ & Sensor elektrik ring Rusak & 90 \\
$\mathbf{8}$ & Panas dari boiler <120 C & 84 \\
$\mathbf{9}$ & Tenaga pengantar silinder kurang dari 5 HP & 84 \\
$\mathbf{1 0}$ & Rem drum tenun tidak bekerja & 75 \\
$\mathbf{1 1}$ & Motor pemutar drum rusak & 72 \\
$\mathbf{1 2}$ & Alat otomatis pergantian palet rusak & 63 \\
$\mathbf{1 3}$ & Motor pemutar rusak & 54 \\
$\mathbf{1 4}$ & Mesin jahit tidak menjahit dengan baik & 36 \\
\hline
\end{tabular}




\section{Usulan Perbaikan}

Tabel 4. Usulan Perbaikan Berdasarkan RPN

\begin{tabular}{|c|c|c|c|}
\hline Ranking RPN & Moda Kegagalan Potensial & RPN & Usulan Perbaikan \\
\hline 2 & Shuttle rusak & 144 & Membersihkan bagian gun dan sisir pada saat proses pencucukan \\
\hline 4 & Kampas rem rusak & 100 & $\begin{array}{l}\text { - Pembersihan disk break setiap } 5 \text { jam } \\
\text { - Pelumasan hydraulic setiap } 1 \text { bulan }\end{array}$ \\
\hline 6 & Motor penggerak bum hani rusak & 96 & $\begin{array}{l}\text { - Pelumasan pada silinder bearing setiap } 1 \text { bulan sekali } \\
\text { - Membersihkan drum hani setiap } 5 \text { jam sekali pada saat mesin } \\
\text { beroperasi }\end{array}$ \\
\hline 7 & Sensor elektrik ring Rusak & 90 & Pembersihan sensor elektrik dan ring setiap hari \\
\hline 8 & Panas dari boiler $<120^{\circ} \mathrm{C}$ & 84 & Memberi stabilizer voltase 1000Va pada boiler \\
\hline 9 & Tenaga pengantar silinder kurang dari $5 \mathrm{HP}$ & 84 & $\begin{array}{l}\text { - Pembersihan umum setiap } 3 \text { bulan } \\
\text { - Memberi stabilizer voltase } 500 \text { Va pada mesin winding }\end{array}$ \\
\hline 12 & Alat otomatis pergantian palet rusak & 63 & Penggunaan air gun untuk membersihkan mesin palet \\
\hline 13 & Motor pemutar rusak & 54 & Memberi stabilizer voltase 500 Va pada mesin centrifugal \\
\hline 14 & Mesin jahit tidak menjahit dengan baik & 36 & Selalu membersihkan meja mesin dari sisa kain setiap ganti kain baru \\
\hline
\end{tabular}

Setelah mendapatkan ranking dari RPN dalam proses FMEA yaitu memberikan usulan perbaikan terhadap moda kegagalan yang telah diranking urutan prioritas. Hal tersebut bertujuan untuk memperbaiki pengendalian kualitas pada saat ini di perusahaan. Usulan perbaikan tidak hanya diberikan pada nilai di atas 100, tetapi semua moda kegagalan yang sudah teridentifikasi tetap diberikan usulan perbaikan sebagai bahan pertimbangan untuk perusahaan. Pada Tabel 3 telah diketahui urutan prioritas sehingga perlu diberikan usulan perbaikan lebih lanjut. Uusulan perbaikan yang dilakukan berdasarkan dari urutan prioritas dapat dilihat pada Tabel 4.

\section{Kesimpulan}

Moda kegagalan potensial pada proses pembuatan sarung tenun ATM pada PT. Asaputex Jaya terdiri dari 14 jenis kegagalan. Moda kegagalan tersebut didapatkan berdasarkan dari kegagalan fungsi alat/proses jenis mesin yang beroperasi pada proses pembuatan sarung tenun. Moda kegagalan pada mesin relling yaitu tenaga mesin relling kurang dari $5 \mathrm{HP}$, pada proses pewarnaan yaitu panas dari boiler $<120^{\circ}$ dan motor pemutar drum rusak. Pada proses pemerasan terdapat moda kegagalan motor pemutar rusak. Pada mesin winding yaitu tenaga pengantar silinder kurang dari 5HP. Pada mesin warping moda kegagalan yaitu sensor elektrik ring, kampas rem, dan motor penggerakbum hani yang rusak. Pada mesin pirn winder yaitu alat otomatis pergantian palet dan motor penggerak pemintal palet rusak. Pada proses weaving dan pencucukan terdapat rem drum teun tidak bekerja, shuttle rusak dan connecting patah. Moda kegagalan yang terakhir pada proses pemotongan dan penjahitan yaitu mesin jahit tidak menjahit dengan baik.

Resiko kegagalan pada hasil FMEA digunakan sebagai prioritas dalam usulan perbaikan. Untuk resiko kegagalan terbesar pada RPN FMEA adalah yang memiliki nilai RPN diatas 100 yaitu connecting patah, shuttle rusak, motor penggerak pemintal palet rusak dan kampas rem rusak. Akan tetapi, semua moda kegagalan yang teridentifikasi tetap diberikan usulan perbaikan disesuaikan dengan kondisi perusahaan.

Usulan perbaikan yang diberikan untuk perusahaan secara keseluruhan adalah perusahaan agar lebih memerhatikan perawatan mesin agar mesin terhindar dari kegagalan fungsinya. Untuk mesin pirn winder diperlukan peralatan bantuan untuk proses perawatan yaitu dengan menggunakan air gun. Sedangkan peralatan lain bantuan yang lain adalah dengan menggunakan stavolt yaitu pada mesin dyeing, mesin winding dan mesin centrifugal.

\section{Daftar Pustaka}

Gasperz, Dr. Vincent, DSc., CFPIM, CIQA. 2005. Total Quality Management. Jakarta : PT Gramedia Pustaka Utama.

Stamatis, D. H. 1995. Failure Mode and Effect Analysis : FMEA from Theory to Execution. Milwaukee : ASQC Quality Press 